\title{
Differences in quality of life in home- dwelling persons and nursing home residents with dementia - a cross-sectional study
}

Christine Olsen ${ }^{1 *}$, Ingeborg Pedersen ${ }^{1}$, Astrid Bergland ${ }^{2}$, Marie-José Enders-Slegers ${ }^{3}$, Nina Jøranson, Giovanna Calogiurit and Camilla Ihlebæk ${ }^{1,5}$

\begin{abstract}
Background: Dementia often eventually leads to dependency on others and finally to residential care. However, in Norway about half of the dementia population lives at home, due to individual and political wishes. There is scarce and inconclusive knowledge of how living in a nursing home differs from living at home for persons with dementia (PWDs) with regard to their quality of life (QoL). The first aim of the study was therefore to compare QoL, cognitive and physical functions, social contacts, sleep patterns, physical activity levels, exposure to light, and medication of PWDs in nursing homes and home-dwelling PWDs, and whether living in nursing homes was associated with a lower QoL than living at home for PWDs. A second aim was to examine if possible differences between residencies in QoL were consistent over time.
\end{abstract}

Methods: The cross-sectional study was based on baseline data from two RCT studies of PWDs. A total of 15 nursing homes with adapted units for PWDs and 23 adapted day care centres for home-dwelling PWDs recruited 78 and 115 participants respectively. Trained nurses scored sociodemographic data, level of dementia (on the Clinical Dementia Rating scale), amount of medication, and QoL (QUALID). Sleep patterns, physical activity levels, and light exposure were measured by actigraphy. A multiple regression analysis was used to test the association between residency and QoL. The association between residency and change in QoL over time was investigated by linear regression analysis of a subsample with follow-up data.

Results: Home-dwelling PWDs showed significantly higher QoL than PWDs in nursing homes. This difference was maintained even after stratifying on the severity of dementia. Home-dwelling PWDs with moderate dementia showed significantly less use of walking aids, more social contact, higher levels of activity and exposure to daylight, and less use of psychotropic medications. The regression model explained $28 \%$ of the variance in QoL in persons with moderate dementia. However, only residency contributed significantly in the model. Residency also significantly predicted negative change over time in QoL.

Conclusion: The study indicated that living at home as long as possible is not only desirable for economic or health political reasons but also is associated with higher QoL for persons with moderate dementia. More studies are needed to investigate how QoL could be increased for PWDs in nursing homes.

Keywords: Dementia, Geriatrics, Nursing home, Home-dwelling, ActiGraph, Institutionalization, Sleep, Light exposure, Activity level, Quality of life

\footnotetext{
* Correspondence: christine.olsen@nmbu.no

'Department of Landscape Architecture and Spatial Planning, Section for

Public Health Science, Norwegian University of Life Sciences, PO Box 5003

NO-1432 Ås, Norway

Full list of author information is available at the end of the article
} 


\section{Background}

Dementia is among the leading causes of disability and death in the elderly [1, 2], and there are currently 47.5 million people with dementia worldwide [3]. There is no cure for dementia [4], and development of dementia eventually leads to a loss of cognitive and physical functions $[5,6]$. This in turn will often lead to total dependency on others and finally to residential care [7]. In Norway, $80 \%$ of nursing home residents suffer from dementia [8].

The incidence of institutionalization varies between European countries [9], and in Norway a higher percentage of the elderly live in nursing homes compared to in other countries [10]. However, it has been estimated that half of the dementia population in Norway still lives at home [11]. Several studies have evaluated risk factors for the institutionalization of the elderly and persons with dementia (PWDs), and older age, cognitive impairment, poor social support, loss of physical function, and use of medication are all factors associated with increased risks of long-term admission to care facilities [9, 12-14].

Residential care can ensure necessary care and safety when PWDs are dependent on help. However, living in a nursing home will affect the lives of PWDs. Many studies have investigated the effect of nursing home environments on different health and behavioural factors [15-18] and the difference between traditional nursing home and small-scale group living $[19,20]$. However, few studies have investigated the differences in how living in a nursing home differs from living at home with regard to PWDs' quality of life (QoL), and they differ in their conclusions $[21,22]$. Furthermore, few studies have investigated the QoL of home-dwelling PWDs.

There is no standard definition of QoL among PWDs, and the conceptualizations of QoL vary too [23, 24]. However, the definition by Lawton [25], who states that QoL is a multidimensional concept, which in older adults includes behavioural competence, the objective environment, psychological well-being, and perceived QoL, is frequently used [26].

QoL among elderly persons with dementia is often diminished [27], and poor QoL has been found associated with several of the same risk factors as found for institutionalization, such as low cognitive function, impaired mobility, lack of social activities, major depression, and low performance in activities of daily life [28-31].

Another factor known to affect QoL is sleep disorders [32]. Sleep disruption is common among dementia patients [33], and it has been reported that two-thirds of nursing home residents have sleep disturbance problems [34]. Light exposure, which is an important regulator of circadian rhythm, has been reported to affect activity levels and sleep in nursing home residents [16]. Institutionalized older adults have lower levels of physical activity than elderly persons living in community dwellings
$[35,36]$, and it has been reported that nursing home residents spend up to $94 \%$ of their time sitting or lying down during the daytime [37]. A study of 15 nursing homes revealed that most of the residents spent at least $17 \mathrm{~h}$ per day in bed [38]. Another factor that might affect QoL is medication, and some pharmacological treatments have been found associated with lower QoL [39]. In addition to these risk factors, both institutionalization and increased dependency might be negatively related to QoL [21, 40], although for some PWDs admission to long-term facilities might increase their QoL [21].

An important goal in dementia care is to provide for and ensure a good quality of life [40], and it is a common political goal among European governments to enable PWDs to live at home as long as possible [10]. It is therefore important to gain more knowledge of QoL and known associated risk factors in PWDs living at home and living in nursing homes. Furthermore, more studies are needed to investigate the association between residential care and QoL when other risk factors are taken into consideration. The first aim of this article was therefore to compare QoL, cognitive and physical function, social contact, sleep patterns, physical activity, light exposure, and medication in PWDs in nursing homes and home-dwelling PWDs, and examine whether residency was associated with QoL. A second aim was to investigate the association between residency and change in QoL over time.

\section{Method}

Our study was based on data from two RCT studies of PWDs in nursing homes and home-dwelling PWDs in Norway (RCTs registered at ClinicalTrial.gov; NCT02008630 and NCT01998490).

\section{Recruitment and subjects}

In Norway, the municipalities are legally responsible for providing domiciliary and residential care, and the administration of nursing homes and day care centres is organized within the municipalities' public health services. Most patients receive domiciliary care for as long as possible prior to admittance to a nursing home. The municipalities' health care and other care services in cooperation with patients' general practitioners assess patients' need for residential care. Most nursing homes have both ordinary units and special care units, and often include day care facilities. Special care units are adapted units that usually only house 7-8 PWDs.

For our study, the county development centres for dementia care in three counties in the south-eastern part of Norway were responsible in recruiting nursing homes and day care centres in their municipalities. All nursing homes and day care centres in the three counties were 
invited to participate in the study, and 15 nursing homes with adapted units for PWDs and 23 adapted day care centres for home-dwelling PWDs were willing to participate.

Each participating institution was asked to recruit between 5 and 8 participants. The inclusion criteria were: aged 65 years or older and either a diagnosis of dementia or a cognitive deficit measured as a score less than 25 on the Mini-Mental State Examination test [41-43].

A total of 209 participants were recruited (88 PWDs living in a nursing home (PWD NH), and 121 homedwelling PWDs). Due to death or because of withdrawal from the study, 16 participants were excluded from the analyses, which meant that data relating to 193 participants (78 PWD NH and 115 home-dwelling PWDs) were included in the analyses. Home-dwelling participants all took part in a day care centre programme at least once per week. The baseline data collection was carried out in winter-spring $2013(N=43$ (PWD NH = 17, home-dwelling PWDs=26)), autumn-winter 2013 $(N=78$ (PWD $\mathrm{NH}=31$, home-dwelling PWDs $=47))$, and spring-summer 2014 $(N=72 \quad$ (PWD $\quad \mathrm{NH}=30$, home-dwelling PWDs=42)), mainly due to practical limitations and to avoid seasonal biases. In addition, a subsample consisting of 11 PWDs in nursing homes and 8 home-dwelling PWDs that were randomized to control groups (treatment as usual) was assessed for QoL 6 months after baseline.

\section{Assessments and procedures for data collection}

The participating patients' primary nurses scored all psychometric assessments and collected information on the participants' age, gender, educational level, use of walking aids, and social encounters. Before the project, they all participated in mandatory education on the use of the instruments.

Quality of life (QoL) was measured using the Norwegian version of the Quality of Life in Late-stage Dementia (QUALID) scale [44, 45]. The proxy rating scale consists of 11 items that are rated on a five-point scale. The items are rated by frequency of occurrence, comprising both positive and negative dimensions of concrete and observable mood and performance. Scores are summed to range from 11 to 55 , Cronbach's alpha $=.815$ (nursing home $=.764$, home-dwelling $=.719$ ). A lower score indicates a higher quality of life.

The Clinical Dementia Rating (CDR) scale, is a 5point scale used to assess six domains of cognitive and functional performance relating to dementia [46-48]. CDR staging is a valid substitute for a dementia assessment among nursing home residents when rating dementia and determine the severity of dementia [47, 48]. A CDR global score of 0 implies no cognitive impairment, $0.5=$ very mild dementia, $1=$ mild dementia, $2=$ moderate dementia, and $3=$ severe dementia. Before the analyses, the CDR scores were recoded into three groups: mild (0, 0.5 and 1), moderate (2), and severe dementia (3).

Actigraphy (ActiSleep+, ActiGraph, Pensacola, US) was used to measure sleep patterns, physical activity levels, and light exposure. ActiSleep + is a validated 3axis accelerometer, which has approximately the shape and size of a wrist watch and delivers advanced data about the wearer's movements over time and their exposure to light. The use of actigraphy for monitoring sleep is validated [49], also for dementia patients [50]. The ActiSleep + was worn on the left wrist continuously for 7 days (epoch-length $1 \mathrm{~min}$ ). Participants were free to remove the ActiSleep + device but were encourage not to do so. Relatives and caregivers were instructed to encourage the participants to put it back on if it had been removed. Before the measurements started, ActiSleep + was introduced orally, visually, and in written form to the participants by their primary nurse, as well as by their relatives and caregivers.

The actigraphy data were processed using the Scoring and Sleep functions of ActiLife, software Version 6.11.2 (ActiGraph, Pensacola, USA), after applying the Wear Time Validation tool. Days with more than $8 \mathrm{~h}$ recorded were included in the further analyses in order to ensure that the activity pattern for those days reflected the participant's typical behaviour pattern. All subjects included in the analysis had at least three valid days and nights.

Total sleep time (TST) is the amount of actual sleep during the night-time, measured in hours. The term 'wake after sleep onset' (WASO) defines the amount of time spent awake after sleep has been initiated and before final awakening; it sums all wake epochs in minutes. The default algorithm of ActiLife may have problems with analysing the sleep-wake schedule. For that reason, we manually inspected all awakenings and created a new variable called 'Number of awakenings $>5$ min'. By using a minimum awake time of 5 min, we ensured that the number of awakenings were accurate. 'Sleep efficiency' was defined as the number of sleep minutes divided by the total number of minutes when the participant was in bed, and was expressed as a percentage. Because of the challenge of identifying a precise bedtime and getup-up time among the home-dwelling population, a default time-in-bed period was arbitrarily set as 23:00 to 06:00 h. Therefore, in our study, sleep efficiency referred to the minutes of sleep within the default time period, and not the patients' actual time spent in bed, and below this is referred to as the 'Sleep during night period'.

Physical activity levels were calculated using the Freedson Adult Cut Points [51] in ActiLife software, and applying a time filter between 08:00 and 20:00 for each monitored day. ActiLife calculates three activity levels 
based on the frequency and intensity of the movement. These constitute the measure 'counts', which are specified as 'counts per minute' (cpm). 'Sedentary activity level' is time in percentage with no physical activity (standardized cut point value: $0-99 \mathrm{cpm}$ ). 'Light activity level' is defined as light intensity activity (standardized cut point value: $100-1951 \mathrm{cpm}$ ). Activities in this category could, for example, be standing or household activities. 'Moderate activity' (standardized cut point value: $1952-5724 \mathrm{cpm}$ ) equates to physical activity, such as walking at $4 \mathrm{~km} / \mathrm{h}$. The Freedson Adult Cut Points can also include measures of 'Vigorous' activity and 'Very vigorous' activity, but these were not used in the study because none of the participants scored any activity at this level. The absolute time (minutes) spent on the different activity levels was subsequently expressed as a percentage of the overall monitoring time.

Light exposure was recorded every second and measured in counts, giving 'lux average counts', which indicated the participants' level of exposure to light.

Records of patients' use of psychotropic medication (antipsychotics, antidepressants, anxiolytics, and hypnotics/sedatives) were collected (from no/yes responses) and a score for number of different types of psychotropic medications (0-4) was constructed.

\section{Ethics}

All participants were informed that they could withdraw from the study at any stage. The ActiGraph device worn by the participants did not register what type of activity they engaged in or their localization, and therefore the usage was not considered invasive.

\section{Analyses}

All statistical analyses were performed using IBM SPSS Statistics Version 23.0 for Windows (Armonk, NY: IBM Corp). Cronbach's alpha was calculated for all sum scores. Group differences between PWD NH and homedwelling PWDs were tested with one-way ANOVA for continuous variables' and with chi-square for categorical data. Stratified analyses of the three categories of cognitive level derived from the CDR test were conducted for variables showing significant differences between groups.

A multiple regression analysis was used to test the association between institutionalization and QoL. This model was only tested for PWDs with moderate dementia, due to the low number of persons with mild dementia in nursing homes and low number of persons with severe dementia living at home. Age, gender and variables that were significantly different between the two groups of PWDs in the bivariate analysis, namely social encounters, use of walking aids, physical activity level (moderate), light exposure, and medication, were entered into the analysis in order to control for these factors.
Before the analysis, dichotomous variables for walking aids (no/yes) and social contacts ( $<$ once per week/ $\geq$ once per week) were constructed. Collinearity statistics showed acceptable values (max VIF $<2.3$ ). Heteroscedasticity was not observed.

The association between residency and change in QoL was investigated by linear regression analysis of the subsample with follow-up data $(n=19)$. Change in QUALID was used as the dependent variable, and residency was entered as predictor variable. In order to control for different baseline levels in QoL, the QUALID baseline score was included in the analysis.

\section{Results}

\section{Group characteristics}

There were no significant age, gender, or educational differences between PWDs in nursing homes and homedwelling PWDs (Table 1). Approximately half of the home-dwelling PWDs lived alone (52.2 \%), but they had significantly more social contact with their family members and friends than nursing home PWDs. Walking aids were used by a significantly higher number of PWDs living in nursing homes than home-dwelling PWDs (Table 1). Significant differences were observed in the severity of dementia: $9 \%$ PWDs living in nursing homes had mild dementia, $43.6 \%$ had moderate dementia, and $47.4 \%$ had severe dementia. By contrast, the respective percentages for home-dwelling PWDs were $43.5 \%$, $47.0 \%$, and $4.3 \%$ (Table 1 ).

\section{QoL, sleep patterns, physical activity, light exposure, and medication}

In the whole sample, PWDs living in nursing homes showed a significantly lower QoL than home-dwelling PWDs (Table 1). They also scored significantly lower on all sleep parameters, except for 'Wake $>5$ min'. PWDs living in nursing homes experienced almost four times less light exposure compared with home-dwelling PWDs. The actigraphy results showed that PWDs living in nursing homes were less active than and showed significantly more sedentary and less active behaviour than home-dwelling PWDs (Table 1). There were also a significant difference in use of psychotropic medication between PWDs living in nursing homes and home-dwelling PWDs, both in the prevalence and number of medications used (Table 1).

Because of the substantial differences in the severity of dementia between the two populations, a stratified analysis on CDR was conducted to look at differences between the two groups with regard to their cognitive levels (Table 2). PWDs living in nursing homes showed a significantly lower QoL for all three categories of severity of dementia and for the category moderate dementia, they had significantly more use of walking aids, less 
Table 1 Demographic data, quality of life (QUALID), and ActiGraph data relating to persons with dementia in nursing homes (PWD NH) and persons with dementia living at home (home-dwelling PWDs)

\begin{tabular}{|c|c|c|c|}
\hline & PWD NH & Home-dwelling PWDs & $p$-value \\
\hline \multicolumn{4}{|l|}{ Demographic data } \\
\hline Women (\%) & $52(66.7)(n=78)$ & 74 (64.3) ( $n=115,1$ missing) & 0.877 \\
\hline Age Mean (SD) & $84.6(6.50)(n=78)$ & $82.6(6.84)(n=103,12$ missing $)$ & 0.803 \\
\hline Education (\%) & $n=78$ & $n=115$ & 0.226 \\
\hline Below upper secondary school & $40(51.3)$ & $43(37.4)$ & \\
\hline Upper secondary school & $10(12.8)$ & $21(18.3)$ & \\
\hline Above upper secondary school & $12(15.4)$ & $28(24.3)$ & \\
\hline Missing & $16(20.5)$ & $23(20.0)$ & \\
\hline Quality of life & $(n=77)$ & $(n=109)$ & \\
\hline QUALID (SD) & $24.06(7.13)$ & $15.99(4.33)$ & $<0.001$ \\
\hline Clinical Dementia Rating (CDR) scale (\%) & $n=78$ & $n=115$ & $<0.001$ \\
\hline Mild & $7(9.0)$ & $50(43.5)$ & \\
\hline Moderate & $34(43.6)$ & $54(47.0)$ & \\
\hline Severe & $37(47.4)$ & $6(5.2)$ & \\
\hline Missing & $0(0)$ & $5(4.3)$ & \\
\hline Walking aids (\%) & $n=78$ & $n=115$ & $<0.001$ \\
\hline None & $24(30.8)$ & $69(60)$ & \\
\hline Walking sticks/Cane/Crutches & $7(9)$ & $19(16.5)$ & \\
\hline Rollator/High walker & $37(47.4)$ & $21(18.3)$ & \\
\hline Wheelchair & $9(11.5)$ & $0(0)$ & \\
\hline Needs support walking & $1(1.3)$ & $0(0)$ & \\
\hline Missing & $0(0)$ & $6(5.2)$ & \\
\hline Social contact with family/friends (\%) & $n=78$ & $n=115$ & $<0.001$ \\
\hline Every day & $5(6.4)$ & $39(33.9)$ & \\
\hline Several times per week & $20(25.6)$ & $48(41.7)$ & \\
\hline Once per week & $31(39.7)$ & $14(12.2)$ & \\
\hline Once every other week & $8(10.3)$ & $2(1.7)$ & \\
\hline Rare & $11(14.1)$ & $5(4.3)$ & \\
\hline Never & $0(0)$ & $0(0)$ & \\
\hline Missing & $3(3.8)$ & $7(6.1)$ & \\
\hline Sleep patterns & $(n=71)$ & $(n=105)$ & \\
\hline Sleep during night-time, Mean (SD) & $75.89(15.46)$ & $80.01(11.88)$ & 0.048 \\
\hline Total sleep time in hours, Mean (SD) & $5.31(1.08)$ & $5.60(0.08)$ & 0.046 \\
\hline WASO in minutes, Mean (SD) & $93.24(59.47)$ & $73.36(42.48)$ & 0.011 \\
\hline Wake $>5$ min & $4.67(2.80)$ & $4.18(2.12)$ & 0.190 \\
\hline Activity pattern & $(n=71)$ & $(n=107)$ & \\
\hline Sedentary \% (SD) & 51.87 (19.78) & $43.51(14.62)$ & 0.001 \\
\hline Light \% (SD) & $45.78(17.70)$ & $50.20(11.69)$ & 0.045 \\
\hline Moderate \% (SD) & $2.35(4.31)$ & $6.29(5.98)$ & $<0.001$ \\
\hline
\end{tabular}


Table 1 Demographic data, quality of life (QUALID), and ActiGraph data relating to persons with dementia in nursing homes (PWD NH) and persons with dementia living at home (home-dwelling PWDs) (Continued)

\begin{tabular}{llll}
\hline Light exposure (lux av. counts) & $(n=71)$ & $(n=107)$ & $165.88(254.36)$ \\
& $43.63(51.40)$ & $(n=88)$ & $<0.001$ \\
Psychotropic medication & $(n=68)$ & 35.2 & $<0.001$ \\
Use of (\%) & 69.1 & $0.43(0.64)$ & $<0.001$ \\
Number (SD) & $1.12(0.97)$ & $<$
\end{tabular}

Notes: $p<0.05$ (level of significance)

social contact, lower levels of moderate activity, lower levels of light exposure, and higher use of psychotropic medication (Table 2). The same pattern was found for the categories mild and severe dementia, although few differences were found to be significant.

\section{Regression analysis}

The analysis showed that for PWDs with moderate dementia residency was significantly associated with lower QoL after controlling for age, gender, social encounters, use of walking aids, moderate physical activity level, light exposure, and medication. The model explained $28 \%$ of the variance in QoL (Table 3).

When looking at change in QoL over time, residency explained $25 \%$ of the change in QoL among participants with moderate dementia $\left(\mathrm{F}(2,16)=3.993, p=0.039, \mathrm{R}^{2}\right.$ Adjusted $=.25$ ). Nursing home PWDs' mean change in QoL was 1.73, while home-dwelling PWDs' mean change was -0.38 . The analysis shows that both baseline score on QUALID and institutionalization did significantly predict change in QUALID during 6 months (Beta $=-0.63$, $\mathrm{t}(19)=-2.66, \mathrm{p}<.05)$ and $($ Beta $=-0.51, \mathrm{t}(19)=-2.16$, $\mathrm{p}<.05)$ (data not shown).

\section{Discussion}

PWDs living in nursing homes showed significantly lower QoL for all three categories of severity of dementia compared to home-dwelling PWDs. In the group with moderate dementia, PWDs living in nursing homes had significantly more use of walking aids, less social contact, lower level of moderate activity, lower levels of light exposure, and a higher use of psychotropic medication. Living in nursing homes was significantly associated with low QoL, even after controlling for several possible confounders, and associations seem to be consistent over time.

Severity of dementia is known to be highly associated with QoL $[27,30]$. We found significantly higher prevalence of severe dementia in nursing home residents than in persons living at home, and similar findings have been reported previously $[11,52]$. Decrease in cognitive functioning such as loss of abilities in memory, judgment, and abstract thinking will lead to need for assistance in many activities of daily life [53], and residential care might be necessary in order to provide the care needed. However, in our study, PWDs living in nursing homes showed lower QoL than PWDs living at home, even after stratifying for severity of dementia. This finding is in line with that of a small study that compared QoL among PWDs with mild dementia living in nursing home or at home and found a significant difference in QoL and social contact between the two groups [54].

Several other factors showed significant differences between home-dwelling PWDs and PWDs living in nursing homes after stratifying for severity of dementia, and this finding might be associated with the differences in QoL. For PWDs with moderate dementia, we found that those who were home-dwelling had significantly less use of walking aids and higher level of moderate activity than those living in nursing homes. These differences might indicate that even though the degree of dementia was the same, the PWDs living in nursing homes had poorer physical function. Poor physical function and dependency has been found associated with low QoL [55], but is also a predictor for nursing home admission [9, 13, 14, 56]. In our study, PWDs living in nursing homes had a lower frequency of social contact, and lack of social support is also known to be a predictor for institutionalization [7]. The higher use of psychotropic medication found among PWDs living in nursing homes compared with home-dwelling PWDs is in line with previous studies [57, 58]. Halvorsen et al. suggest that such differences in medication could be explained by more prevalent behavioural and psychiatric symptoms (BPSD) in PWD NH [58]. We did not have any measurements on BPSD for the home-dwelling population and therefore could not compare the two groups on these factors. This constituted a weakness in our study, as BPSD is known to affect patients' quality of life (QoL) $[40,52]$ and might also be associated with institutionalization $[13,56]$.

One European study investigating how QoL varied according to living arrangements concluded that there were no clinically significant differences in QoL between PWDs living in nursing homes and home-dwelling PWDs [21]. However, in our study, living in a nursing 
Table 2 Quality of life, medication, use of walking aids, social contact, and ActiGraph data stratified on CDR, mean (SD)

\begin{tabular}{|c|c|c|c|c|c|c|c|c|c|}
\hline & \multicolumn{3}{|l|}{ Mild dementia } & \multicolumn{3}{|c|}{ Moderate dementia } & \multicolumn{3}{|c|}{ Severe dementia } \\
\hline & $\mathrm{NH}$ & Home-dwelling & $p$-value ${ }^{*}$ & $\mathrm{NH}^{* *}$ & Home-dwelling & $p$-value & $\mathrm{NH}$ & Home-dwelling & $p$-value \\
\hline Quality of life & $18.86(6.41)$ & $14.89(3.74)$ & 0.022 & $21.94(6.22)$ & $16.66(4.37)$ & $<0.001$ & $26.95(6.94)$ & $18.67(5.82)$ & 0.009 \\
\hline Walking aids (\%) & 57.1 & 47.9 & .265 & 70.6 & 25.5 & $<0.001$ & 70.3 & 33.3 & 0.004 \\
\hline Social contact weekly (\%) & 42.9 & 97.9 & $<0.001$ & 81.8 & 90.4 & 0.004 & 74.3 & 80.0 & 0.058 \\
\hline \multicolumn{10}{|l|}{ Sleep patterns } \\
\hline Sleep during night-time (\%) & $76.68(16.54)$ & $79.43(11.52)$ & 0.579 & $76.77(15.51)$ & $79.22(12.84)$ & 0.453 & $75.95(14.68)$ & $86.86(3.76)$ & 0.111 \\
\hline Total sleep time in minutes & $322.04(69.45)$ & $333.61(48.37)$ & 0.579 & $322.41(65.16)$ & $333.07(53.96)$ & 0.438 & $318.99(61.64)$ & $364.81(15.77)$ & 0.111 \\
\hline WASO ${ }^{* * *}$ (minutes) & $92.84(68.17)$ & $75.71(37.94)$ & 0.323 & $89.75(59.95)$ & $75.02(48.94)$ & 0.242 & $93.84(57.87)$ & $53.47(16.90)$ & 0.135 \\
\hline Wake $>5$ min & $4.61(2.78)$ & $4.31(1.74)$ & 0.694 & $4.88(2.61)$ & $4.16(2.50)$ & 0.229 & $4.49(3.04)$ & $3.20(1.83)$ & 0.363 \\
\hline \multicolumn{10}{|l|}{ Activity pattern } \\
\hline Sedentary (\%) & $41.44(21.17)$ & $43.01(14.27)$ & 0.800 & $47.63(16.67)$ & $43.71(15.14)$ & 0.281 & $58.06(20.76)$ & $48.2(15.52)$ & 0.317 \\
\hline Light (\%) & $52.55(17.95)$ & $50.26(10.8)$ & 0.634 & $49.74(14.21)$ & $50.12(12.17)$ & 0.900 & $40.62(19.58)$ & $49.15(14.35)$ & 0.357 \\
\hline Moderate (\%) & $6.01(7.8)$ & $6.73(6.8)$ & 0.797 & $2.63(4.72)$ & $6.17(5.36)$ & 0.003 & $1.32(2.08)$ & $2.65(2.05)$ & 0.191 \\
\hline Light exposure (lux av. counts) & $93.49(102.91)$ & $142.55(211.55)$ & 0.551 & $39.12(44.39)$ & $171.84(275.17)$ & 0.010 & $37.28(36.63)$ & $300.15(328.12)$ & $<0.001$ \\
\hline Psychotropic medication & $1.17(0.98)$ & $0.54(0.61)$ & 0.042 & $1.17(1.09)$ & $0.32(0.60)$ & $<0.001$ & $1.06(0.88)$ & $0.40(0.89)$ & 0.126 \\
\hline
\end{tabular}

Notes: ${ }^{*} p<0.05$ (level of significance); ** nursing home, ${ }^{* * *}$ wake after sleep onset 
Table 3 Association between age, gender, use of walking aids, social contacts, activity level, light exposure, medication, and residency with QUALID in persons with moderate dementia $(N=61)$

\begin{tabular}{lll}
\hline Variables & $\beta$ & $\mathrm{p}$ \\
\hline Age & -.001 & .991 \\
Gender & .028 & .806 \\
Use of walking aids $^{\mathrm{a}}$ & -.014 & .922 \\
Social contact $^{\mathrm{b}}$ & .139 & .266 \\
Moderate activity $^{c}$ & -.070 & .604 \\
Light exposure $^{c}$ & -.145 & .243 \\
Psychotropic medication $^{c}$ & .090 & .487 \\
Residency $^{\mathrm{d}}$ & -.394 & .023 \\
\hline
\end{tabular}

Notes:

${ }^{a}$ Use of walking aids: $0=$ No, $1=$ Yes

b Social contact: $0=$ Less than once a week, $1=$ Weekly

' High score indicates to high level of moderate activity, high level of

exposure to lux, and high use of psychotropic medication

${ }^{d}$ Nursing home $=0$, Home-dwelling $=1$

Standardized beta was used

$p<0.05$ (level of significance)

Adjusted $\mathrm{R}^{2} .276$

$\mathrm{R}^{2}$ change .373

home was associated with a lower QoL than living at home for persons with moderate dementia, even after controlling for confounding or mediating factors. Being institutionalized might lead to loss of control and lack of autonomy (e.g. when and what to eat, when to sleep, and when to go for a walk), and Heggestad et al. found that many nursing home residents did not feel at home in their unit and missed their former homes [59]. Furthermore, nursing home residents do not often participate in activities and tend to be unoccupied for much of the day [60]. Several studies of institutionalized PWDs have shown that the residents' needs for meaningful activities are often unmet $[15,17,61]$. In the Netherlands it has been shown that small-scale settings provide better environments for social relationships than traditional nursing home settings, and one study revealed that residents had significantly higher scores on the QoL subscale 'positive affect' [62]. However, other studies have found mixed results on the effects of small-scale settings [63], and that residents perceived a more traditional nursing home environment as satisfactory and that being deprived of privacy was not a problem [64].

The longitudinal QoL data from the sub-group with moderate dementia enabled us to take unobserved heterogeneity into account and thereby detect developments or changes in the characteristics of the population. The fact that nursing home residents had a decrease in mean change of QoL, whereas homedwelling PWDs were stable over a 6-month period supports the findings that living in a nursing home affect QoL negatively.

\section{Strengths and limitations}

This study had several limitations. The institutions and the participants were all recruited to participate in two RCTs and might not have been representative of nursing home and home-dwelling populations in general. However, the recruitment procedure and inclusion criteria were the same for both patient groups, which made the groups comparable. Furthermore, the participants' characteristics and level of QoL were in line with findings in other Norwegian studies of persons with dementia $[28,57,65]$, indicating that the sample was representative. All home-dwelling PWDs had activities at a day care centre at least once per week, which means that the sample was not representative of the home-dwelling PWD population as a whole. It should be noted that activities at Norwegian day care centres are usually offered to persons who exhibit higher levels or more severe symptoms of dementia, to ease the burden on the family carers.

Validated psychometric questionnaires were used to measure cognitive impairment (CDR) and QoL (QUALID), but proxy assessments always will have less validity than self-assessments. Assessing QoL in PWDs is often done with proxy assessments due to the assumption that the respondents will not able to complete a self-report. However, research has shown that especially those with mild or moderate dementia are capable of completing such reports, and interestingly PWDs in general report that they have a better QoL than their close relatives or care workers do $[21,26]$. Therefore, we cannot know whether the scoring in our study truly reflected the participants' experience, but the QUALID assessment rates concrete and observable behaviour and is a validated tool for this patient group [45]. In our study the patients' primary nurses scored the psychometric measures, and primary nurses at nursing homes could be expected to have a broad understanding of their patients' cognitive level, behaviour, and mood. However, the nurses at the day care centre only saw their patients once or twice each week and might not have had the same insights into their patients' lives. This could have led to bias if the scoring relating to QoL in home-dwelling PWDs was systematically higher than for nursing home PWDs. However, a previous study found no clinically relevant differences in proxy-reported QoL between those in home care and those in institutional long-term care [21].

Actigraphy gives objective data on physical activity. The use of wrist ActiGraphs has been validated for the evaluation of sleep in patients with dementia [66], and the devices have been used to study motor activity patterns in elderly patients with dementia both living in nursing homes and living at home [67, 68]. A specific problem of using actigraphy in this particular patient group could be the removal of the wrist device. We 
excluded days that had less than $8 \mathrm{~h}$ recorded after applying ActiLife's Wear Time Validation tool (21.75 \% of the total number of days); hence, removal of the wrist ActiGraph was not considered a substantial problem. Also, we had to rely on an arbitrary setting of 'time in bed', which on the one hand allowed us to obtain a more standardized measure of the amount of sleep during more 'desirable' hours of the day or night, but on the other hand did not fully return a measurement of the participants' actual sleep efficacy. This would have to be taken into account if the findings were to be compared with those in the existing literature.

The model explained $28 \%$ of the variance in QoL, which indicates that other factors not included in the study affected QoL in the patient group. It is reasonable to assume that the PWDs living in nursing homes had poorer health in general, and more comorbid somatic diseases, as might be indicated by the significant differences between the groups in medication and use of walking aids. However, comorbidity and number of diagnoses were not found associated with QoL in another Norwegian study of patients with dementia in nursing homes [31], and earlier research has shown inconsistent associations between medication and QoL in PWDs [21, 31, 40].

Finally, the cross-sectional design of the study restricted the possibility of drawing any conclusions on causality, and the only conclusion that could be derived from the regression model is that living in nursing home is associated with lower QoL. However, the results of the longitudinal analysis conducted on the subgroup population could suggest that residential care contributes in a causal way toward lower QoL.

\section{Conclusion}

The results of our study indicate that living at home as long as possible is not only desirable for economic and/ or health political reasons but also is associated with a higher QoL for patients with moderate dementia. More studies are needed to investigate how QoL could be increased for PWDs living in nursing homes.

\section{Abbreviations}

QoL, quality of life; PWDs, persons with dementia; PWD NH, persons with dementia in nursing homes; CDR, The Clinical Dementia Rating scale

\footnotetext{
Acknowledgements

The authors thank the cooperating partners, institutions, health workers, and participants.

\section{Funding}

The project was funded by grant no. 217516 from the Oslofjordfondet and RFF Hovedstaden, NMBU, and cooperating partners (The Norwegian Centre of Anthrozoology, Buskerud and Vestfold University College, Centre for Development of Institutional and Home Care Services in Vestfold and Nøtterøy Municipality). Cooperating partners supported the project with internal financing.
}

\section{Availability of data and materials}

Data supporting the findings is available upon request. Please contact the first author Christine Olsen (christine.olsen@nmbu.no) for data availability.

\section{Authors' contributions}

$\mathrm{CO}, \mathrm{Cl}$ and IP contributed to the study design, CO, IP, GC and NJ contributed to data collection, CO, IP, GC, and $\mathrm{Cl}$ contributed to data analysis and data interpretation. All co-authors contributed to the writing process. The first author took part in the whole process. All authors read and approved the final manuscript.

\section{Competing interests}

The authors declare that they have no competing interests.

\section{Consent for publication}

Not applicable.

\section{Ethics approval and consent to participate}

The project was performed in accordance with the Helsinki Declaration, and the project was approved by the Regional Committee for Medical Ethics in south-east Norway. Associated health staff allocated eligible participants, provided information about the study, and gathered written consent. Written and verbal information about the study was given to potential participants and their relatives by their primary caregivers. A procedure for care workers was developed for evaluating potential participants' cognitive capacity to give informed written consent. Those with sufficient cognitive capacity were informed about the project and gave written consent to participate. For those with reduced capacity, their care workers and/or their next-of-kin took the decision on their behalf and gave written consent when appropriate.

\section{Author details}

${ }^{1}$ Department of Landscape Architecture and Spatial Planning, Section for Public Health Science, Norwegian University of Life Sciences, PO Box 5003 NO-1432 Ås, Norway. ${ }^{2}$ Faculty of Health Sciences, Oslo and Akershus University College, Oslo, Norway. ${ }^{3}$ Psychology and Educational Sciences, Open University of the Netherlands, Heerlen, Netherlands. ${ }^{4}$ Department of Dental Care and Public Health, Hedmark University College, Elverum, Norway. ${ }^{5}$ Faculty of Health and Social Work Studies, Østfold University College, Fredrikstad, Norway.

Received: 23 December 2015 Accepted: 6 July 2016

Published online: 11 July 2016

\section{References}

1. Fratiglioni L, Launer $L$, Andersen K, Breteler MM, Copeland JR, Dartigues JF, Lobo A, Martinez-Lage J, Soininen H, Hofman A. Incidence of dementia and major subtypes in Europe: A collaborative study of population-based cohorts. Neurologic Diseases in the Elderly Research Group. Neurology. 2000;54(11 Suppl 5):S10-15.

2. Colantuoni E, Surplus G, Hackman A, Arrighi HM, Brookmeyer R. Web-based application to project the burden of Alzheimer's disease. Alzheimer Dement. 2010;6(5):425-8. doi:10.1016/j.jalz.2010.01.014.

3. Dementia Fact sheet $N^{\circ} 362$ [http://www.who.int/mediacentre/factsheets/ fs362/en/]. 10.12. 2015

4. Geldmacher DS, Frolich L, Doody RS, Erkinjuntti T, Vellas B, Jones RW, Banerjee S, Lin P, Sano M. Realistic expectations for treatment success in Alzheimer's disease. J Nutr Health Aging. 2006;10(5):417-29.

5. McKhann G, Drachman D, Folstein M, Katzman R, Price D, Stadlan EM. Clinical diagnosis of Alzheimer's disease: report of the NINCDS-ADRDA Work Group under the auspices of Department of Health and Human Services Task Force on Alzheimer's Disease. Neurology. 1984;34(7):939-44.

6. van lersel MB, Hoefsloot W, Munneke M, Bloem BR, Olde Rikkert MG Systematic review of quantitative clinical gait analysis in patients with dementia. Z Gerontol Geriatr. 2004;37(1):27-32. doi:10.1007/s00391-004-0176-7.

7. Hajek A, Brettschneider C, Lange C, Posselt T, Wiese B, Steinmann S, Weyerer S, Werle J, Pentzek M, Fuchs A et al. Longitudinal Predictors of Institutionalization in Old Age. PLoS One. 2015;10(12):e0144203. doi:10.1371/ journal.pone.0144203.

8. Selbæk G, Kirkevold $\varnothing$, Engedal K. The prevalence of psychiatric symptoms and behavioural disturbances and the use of psychotropic drugs in Norwegian nursing homes. Int J Geriatr Psychiatry. 2007;22(9):843-9. 
9. Verbeek H, Meyer G, Challis D, Zabalegui A, Soto ME, Saks K, Leino-Kilpi H, Karlsson S, Hamers JP. Inter-country exploration of factors associated with admission to long-term institutional dementia care: evidence from the RightTimePlaceCare study. J Adv Nurs. 2015;71(6):1338-50. doi:10.1111/jan.12663.

10. Knapp M, Comas-Herrera A, Somani A, Banerjee S: Dementia: international comparisons: summary report for the National Audit Office. In. London; 2007: 19

11. Lystrup LS, Lillesveen B, Nuygård A-M, Engedal K. Omsorgstilbud til hjemmeboende personer med demens. Tidsskr Nor Laegeforen. 2006; 126(15):1917-20

12. Bharucha AJ, Pandav R, Shen C, Dodge HH, Ganguli M. Predictors of Nursing Facility Admission: A 12-Year Epidemiological Study in the United States. J Am Geriatr Soc. 2004;52(3):434-9. doi:10.1111/j.1532-5415.2004.52118.x.

13. Wergeland JN, Selbaek G, Bergh S, Soederhamn U, Kirkevold O. Predictors for Nursing Home Admission and Death among Community-Dwelling People 70 Years and Older Who Receive Domiciliary Care. Dement Geriatr Cogn Dis Extra. 2015;5(3):320-9. doi:10.1159/000437382

14. Hajek A, Brettschneider C, Ernst A, Posselt T, Wiese B, Prokein J, Weyerer S, Werle J, Fuchs A, Pentzek M et al.: Longitudinal predictors of informal and formal caregiving time in community-dwelling dementia patients. Social psychiatry and psychiatric epidemiology 2015.10.1007/s00127-015-1138-7

15. Cohen-Mansfield J, Dakheel-Ali M, Marx MS, Thein K, Regier NG. Which unmet needs contribute to behavior problems in persons with advanced dementia? Psychiatry Res. 2015;228(1):59-64. doi:10.1016/j.psychres.2015.03.043.

16. Anderiesen $\mathrm{H}$, Scherder EJ, Goossens $\mathrm{RH}$, Sonneveld MH. A systematic review-physical activity in dementia: the influence of the nursing home environment. Appl Ergon. 2014;45(6):1678-86. doi:10.1016/j.apergo.2014.05.011.

17. van der Ploeg ES, Bax D, Boorsma M, Nijpels G, van Hout HP. A cross-sectional study to compare care needs of individuals with and without dementia in residential homes in the Netherlands. BMC Geriatr. 2013;13:51. doi:10.1186/ 1471-2318-13-51.

18. Willemse BM, Downs M, Arnold L, Smit D, de Lange J, Pot AM. Staff-resident interactions in long-term care for people with dementia: the role of meeting psychological needs in achieving residents' well-being. Aging Ment Health. 2015;19(5):444-52. doi:10.1080/13607863.2014.944088.

19. Verbeek H, Zwakhalen SM, van Rossum E, Ambergen T, Kempen Gl, Hamers JP. Small-scale, homelike facilities versus regular psychogeriatric nursing home wards: a cross-sectional study into residents' characteristics. BMC Health Serv Res. 2010;10:30. doi:10.1186/1472-6963-10-30.

20. Zimmerman S, Anderson WL, Brode S, Jonas D, Lux L, Beeber AS, Watson LC, Viswanathan M, Lohr KN, Sloane PD. Systematic Review: Effective Characteristics of Nursing Homes and Other Residential Long-Term Care Settings for People with Dementia. J Am Geriatr Soc. 2013;61(8):1399-409. doi:10.1111/jgs.12372.

21. Beerens HC, Sutcliffe C, Renom-Guiteras A, Soto ME, Suhonen R, Zabalegui A, Bokberg C, Saks K, Hamers JP. Quality of life and quality of care for people with dementia receiving long term institutional care or professional home care: the European RightTimePlaceCare study. J Am Med Dir Assoc. 2014;15(1):54-61. doi:10.1016/j.jamda.2013.09.010.

22. Beerens HC, Zwakhalen SMG, Verbeek H, Ruwaard D, Ambergen AW Leino-Kilpi H, Stephan A, Zabalegui A, Soto M, Saks K et al. Change in quality of life of people with dementia recently admitted to long-term care facilities. J Adv Nurs. 2015;71(6):1435-47. doi:10.1111/jan.12570.

23. Ettema TP, Droes RM, de Lange J, Ooms ME, Mellenbergh GJ, Ribbe MW The concept of quality of life in dementia in the different stages of the disease. Int Psychogeriatr. 2005;17(3):353-70.

24. Dichter MN, Halek M, Dortmann O, Meyer G, Bartholomeyczik S: Measuring the quality of life of people with dementia in nursing homes in Germany - the study protocol for the Qol-Dem Project. GMS Psycho-Social-Medicine 2013, 10: Doc06.10.3205/psm000096

25. Lawton MP. A multidimensional view of quality of life in frail elders. In: Birren JE, Lubben JE, Cichowlas Rowe J, Deutchman DE, editors. The Concept and Measurement of Quality of Life in the Frail Elderly. San Diego: Academic Press; 1991. p. 3-27.

26. Logsdon RG, Gibbons LE, McCurry SM, Teri L. Assessing quality of life in older adults with cognitive impairment. Psychosom Med. 2002;64(3):510-9.

27. Bárrios H, Narciso S, Guerreiro M, Maroco J, Logsdon R, de Mendonça A. Quality of life in patients with mild cognitive impairment. Aging Ment Health. 2012;17(3):287-92. doi:10.1080/13607863.2012.747083.

28. Barca ML, Engedal K, Laks J, Selbæk G. Quality of life among elderly patients with dementia in institutions. Dement Geriatr Cogn Disord. 2011;31(6): 435-442.10.1159/000328969.
29. Nagatomo I, Kita K, Takigawa M, Nomaguchi M, Sameshima K. A study of the quality of life in elderly people using psychological testing. Int J Geriatr Psychiatry. 1997;12(6):599-608. doi:10.1002/(SICI)1099-1166(199706)12: 6<599::AID-GPS505>3.0.CO;2-E.

30. Mjørud M, Kirkevold M, Rosvik J, Selbæk G, Engedal K. Variables associated to quality of life among nursing home patients with dementia. Aging Ment Health. 2014;18(8):1013-21. doi:10.1080/13607863.2014.903468.

31. Telenius EW, Engedal K, Bergland A. Physical Performance and Quality of Life of Nursing-Home Residents with Mild and Moderate Dementia. Int J Environ Res Public Health. 2013;10(12):6672-86. doi:10.3390/ijerph10126672.

32. Hodgson N, Gitlin LN, Huang J. The influence of sleep disruption and pain perception on indicators of quality of life in individuals living with dementia at home. Geriatr Nurs. 2014;35(5):394-8. doi:10.1016/j. gerinurse.2014.08.005

33. Tractenberg RE, Singer CM, Kaye JA. Symptoms of sleep disturbance in persons with Alzheimer's disease and normal elderly. J Sleep Res. 2005;14(2): 177-85. doi:10.1111/j.1365-2869.2005.00445.x.

34. Dementia and Sleep [Available at: https://sleepfoundation.org/sleepdisorders-problems/dementia-and-sleep].

35. Król-Zielińska M, Kusy K, Zieliński J, Osiński W. Physical activity and functional fitness in institutionalized vs. independently living elderly: A comparison of 70-80-year-old city-dwellers. Arch Gerontol Geriatr. 2010; 53(1):e10-6. doi:10.1016/j.archger.2010.07.013.

36. Salguero A, Martinez-Garcia R, Molinero O, Marquez S. Physical activity, quality of life and symptoms of depression in community-dwelling and institutionalized older adults. Arch Gerontol Geriatr. 2011;53(2):152-7. doi:10. 1016/j.archger.2010.10.005

37. MacRae PG, Schnelle JF, Simmons SF, Ouslander JG. Physical Activity Levels of Ambulatory Nursing Home Residents. J Aging Phys Act. 1996;4(3):264-78.

38. Bates-Jensen BM, Alessi CA, Cadogan M, Levy-Storms L, Jorge J, Yoshii J, Al-Samarrai NR, Schnelle JF. The Minimum Data Set bedfast quality indicator: differences among nursing homes. Nurs Res. 2004;53(4):260-72.

39. Gonzalez-Salvador T, Lyketsos CG, Baker A, Hovanec L, Roques C, Brandt J, Steele C. Quality of life in dementia patients in long-term care. Int J Geriatr Psychiatry. 2000;15(2):181-9.

40. Beerens HC, Zwakhalen SM, Verbeek H, Ruwaard D, Hamers JP. Factors associated with quality of life of people with dementia in long-term care facilities: a systematic review. Int J Nurs Stud. 2013;50(9):1259-70. doi:10. 1016/j.ijnurstu.2013.02.005

41. Folstein M, Folstein S, McHugh P. "Mini-mental state": A practical method for grading the cognitive state of patients for the clinician. J Psychiatr Res. 1975;12:189-98.

42. Strobel C, Engedal K: Norsk revidert Mini Mental Status evaluering (MMSE-NR). In.; 2009.

43. O'Connor DW, Pollitt PA, Treasure FP, Brook CP, Reiss BB. The influence of education, social class and sex on Mini-Mental State scores. Psychol Med. 1989:19(3):771-6.

44. Weiner MF, Martin-Cook K, Svetlik DA, Saine K, Foster B, Fontaine CS. The quality of life in late-stage dementia (QUALID) scale. J Am Med Dir Assoc. 2000;1(3):114-6.

45. Røen I, Selbæk G, Kirkevold O, Engedal K, Lerdal A, Bergh S. The Reliability and Validity of the Norwegian Version of the Quality of Life in Late-Stage Dementia Scale. Dement Geriatr Cogn Disord. 2015;40(3-4):233-242.10. 1159/000437093.

46. Hughes $C P$, Berg L, Danziger WL, Coben LA, Martin RL. A new clinical scale for the staging of dementia. Br J Psychiatry J Ment Sci. 1982;140:566-72.

47. Engedal K, Haugen PK. The prevalence of dementia in a sample of elderly Norwegians. Int J Geriatr Psychiatry. 1993;8:565-70.

48. Nygaard HA, Ruths S. Missing the diagnosis: senile dementia in patients admitted to nursing homes. Scand J Prim Health Care. 2003;21(3):148-52.

49. Natale V, Plazzi G, Martoni M. Actigraphy in the Assessment of Insomnia: A Quantitative Approach. Sleep. 2009;32(6):767-71.

50. Ancoli-Israel S, Clopton P, Klauber MR, Fell R, Mason W. Use of Wrist Activity for Monitoring Sleep/Wake in Demented Nursing-Home Patients. Sleep. 1997;20(1):24-7

51. Freedson PS, Melanson E, Sirard J. Calibration of the Computer Science and Applications, Inc. accelerometer. Med Sci Sports Exerc. 1998;30(5):777-81.

52. Mjørud M, Røsvik J, Rokstad AMM, Kirkevold M, Engedal K. Variables Associated with Change in Quality of Life among Persons with Dementia in Nursing Homes: A 10 Months Follow-Up Study. PLoS ONE. 2014;9(12): e115248. doi:10.1371/journal.pone.0115248. 
53. Andersen C, Wittrup-Jensen K, Lolk A, Andersen K, Kragh-Sorensen P. Ability to perform activities of daily living is the main factor affecting quality of life in patients with dementia. Health Qual Life Outcomes. 2004;2(1):52.

54. Nikmat AW, Hawthorne G, Al-Mashoor SH: Quality of life in dementia patients: nursing home versus home care. International psychogeriatrics/IPA 2011, 23.10.1017/s1041610211001050

55. Logsdon RG, McCurry SM, Teri L. Evidence-Based Interventions to Improve Quality of Life for Individuals with Dementia. Alzheimers care today. 2007; 8(4):309-18.

56. Risco E, Cabrera E, Jolley D, Stephan A, Karlsson S, Verbeek H, Saks K, Hupli M, Sourdet S, Zabalegui A. The association between physical dependency and the presence of neuropsychiatric symptoms, with the admission of people with dementia to a long-term care institution: a prospective observational cohort study. Int J Nurs Stud. 2015;52(5):980-7. doi:10.1016/j. ijnurstu.2015.02.01.

57. Wergeland JN, Selbaek G, Hogset LD, Soderhamn U, Kirkevold O. Dementia, neuropsychiatric symptoms, and the use of psychotropic drugs among older people who receive domiciliary care: a cross-sectional study. Int Psychogeriatr. 2014;26(3):383-91. doi:10.1017/s1041610213002032.

58. Halvorsen KH, Granas AG, Engeland A, Ruths S. Prescribing quality for older people in Norwegian nursing homes and home nursing services using multidose dispensed drugs. Pharmacoepidemiol Drug Saf. 2012;21(9):929-36. doi:10.1002/pds.2232.

59. Heggestad AK, Nortvedt P. Slettebo A: 'Like a prison without bars': dementia and experiences of dignity. Nurs Ethics. 2013;20(8):881-892.10.1177/ 0969733013484484

60. Smit D, de Lange J, Willemse B, Twisk J, Pot AM: Activity involvement and quality of life of people at different stages of dementia in long term care facilities. Aging \& mental health 2015:1-10.10.1080/13607863.2015.1049116

61. Hancock GA, Woods B, Challis D, Orrell M. The needs of older people with dementia in residential care. Int J Geriatr Psychiatry. 2006;21(1):43-9. doi:10. 1002/gps.1421.

62. de Rooij AH, Luijkx KG, Schaafsma J, Declercq AG, Emmerink PM, Schols JM. Quality of life of residents with dementia in traditional versus small-scale long-term care settings: a quasi-experimental study. Int J Nurs Stud. 2012; 49(8):931-40. doi:10.1016/j.ijnurstu.2012.02.007.

63. Verbeek H, Zwakhalen SMG, van Rossum E, Kempen GIJM, Hamers JPH. Small-scale, homelike facilities in dementia care: A process evaluation into the experiences of family caregivers and nursing staff. Int J Nurs Stud. 2012; 49(1):21-9. doi:10.1016/j.jinurstu.2011.07.008.

64. Aggarwal N, Vass AA, Minardi HA, Ward R, Garfield C, Cybyk B. People with dementia and their relatives: personal experiences of Alzheimer's and of the provision of care. J Psychiatr Ment Health Nurs. 2003;10(2):187-97.

65. Miørud M, Kirkevold M, Røsvik J, Engedal K. Principal component analysis of the Norwegian version of the quality of life in late-stage dementia scale. Dement Geriatr Cogn Disord. 2014;37(5-6):265-275.10.1159/000356497.

66. Martin JL, Hakim AD. Wrist actigraphy. Chest. 2011;139(6):1514-27. doi:10. 1378/chest.10-1872.

67. Kuhlmei A, Walther B, Becker T, Muller U, Nikolaus T. Actigraphic daytime activity is reduced in patients with cognitive impairment and apathy. Eur Psychiatry. 2013;28(2):94-7. doi:10.1016/j.eurpsy.2011.04.006.

68. Valembois L, Oasi C, Pariel S, Jarzebowski W, Lafuente-Lafuente C, Belmin J. Wrist Actigraphy: A Simple Way to Record Motor Activity in Elderly Patients with Dementia and Apathy or Aberrant Motor Behavior. J Nutr Health Aging. 2015;19(7):759-64. doi:10.1007/s12603-015-0530-z.

\section{Submit your next manuscript to BioMed Central and we will help you at every step:}

- We accept pre-submission inquiries

- Our selector tool helps you to find the most relevant journal

- We provide round the clock customer support

- Convenient online submission

- Thorough peer review

- Inclusion in PubMed and all major indexing services

- Maximum visibility for your research

Submit your manuscript at www.biomedcentral.com/submit 